\title{
PROPOSTA DE POLÍTICA DE ASSISTÊNCIA TÉCNICA AGRÍCOLA: UM DESAFIO A TÉCNICOS E AGRICULTORES
}

\author{
PROPOSAL OF POLITICS OF AGRICULTURAL \\ TECHNICAL SUPPORT: A CHALLENGE TO \\ TECHNICIANS IS FARMING
}

\author{
Christian Reichmann Sassi*
}

\begin{abstract}
RESUMO
Este trabalho consiste de uma análise sobre a assistência técnica agrícola, relacionada com a forma de atuação dos organismos envolvidos, frente às mudanças que são necessárias atualmente, visando propor uma alternativa de assistência. A assistência é fundamental para que os agricultores evoluam e, oficialmente não consegue atingir eficientemente a grande maioria dos agricultores. O objetivo deste trabalho é mostrar a importância, algumas falhas da assistência técnica e propor uma forma capaz de atender as expectativas dos agricultores, pelo menos em parte, de forma autossustentável. Para isso, efetuouse uma revisão bibliográfica abordando um breve histórico a importância da assistência técnica pública e privada e sua necessidade. Sendo assim propôs-se a formação de um grupo de dez técnicos agrícolas coordenados por um Engenheiro Agrônomo em que cada técnico atenderia dez propriedades rurais de agricultores que aderissem voluntariamente ao programa, totalizando cem propriedades por grupo. Os profissionais seriam contratados pelo Governo do Estado pelo prazo de um ano, findo o qual os agricultores assumiriam os custos. O projeto aposta na capacidade de transformação por meio do conhecimento técnico e humano que os profissionais da área possuem. Conclui-se que a proposta é um desafio e depende do comprometimento dos profissionais e dos agricultores e merece ser posta em prática para validação.
\end{abstract}

Palavras-chave: Assistência técnica. Agricultores familiares. Proposta. Melhoria. Renda.

\begin{abstract}
This paper analyses technical agricultural support, in particular the actions of the organisms involved concerning the necessary changes in order to propose an alternative form of assistance. Assistance is essential so that farmers develop. It is important to highlight mind that, officially, the vast majority of farmers do not
\end{abstract}

\footnotetext{
" Engenheiro Agrônomo Especialista em Formulação e Gestão de Políticas Públicas, Ciência e Tecnologia de Sementes e Plantio Direto. Secretaria de Estado da Agricultura e Abastecimento - SEAB, Núcleo Regional de Ponta Grossa - PR, Departamento de Fiscalização e Defesa Agropecuária, Escritório Local de Castro - Paraná - Brasil. E-mail: <christiansassi@seab.pr.gov.br>
} 
receive any form of assistance. The aim of this paper is to show the importance, some of the failures in technical support and propose a form of meeting the expectations of farmers, at least in part, in a self-sustainable form. In order to this, a literature review presenting a brief history of the importance of technical public and private support and its need. Thus, a group of 10 agricultural technicians coordinated by an agronomist would be organized. Each technician would assist 10 rural properties whose owners voluntarily joined the program; therefore 100 properties per group would be assisted. The professionals would be hired by the government for a year, after this period the farmers would be responsible for the expenses. The project believes in the capacity of transformation using the technical and human knowledge of the professionals of the area. The study demonstrates that the proposal represents a challenge, and it depends on the commitment of professionals and farmers, and it should be put in practice to validate the proposal

Keywords: Technical support. Family farmers. Proposal. Improvement. Income.

\section{Introdução}

Atualmente, a assistência técnica é fundamental em qualquer atividade comercial. Em relação à assistência técnica rural, por suas características próprias, onde se trabalha com um público heterogêneo em condições sociais, econômicas, educacionais e culturais podemos dizer que é uma atividade complexa. Entretanto, se for direcionada para o público certo e partir de suas demandas, pode ser bastante simplificada. É obrigação do Estado propiciar estes serviços para os agricultores familiares, mas entende-se que os processos de se oferecer estes serviços não necessitam ser iguais e homogêneos para todos. Atualmente muitos agricultores não dispõem de assistência técnica e até que estes serviços aconteçam o agricultor não deveria ficar esperando. Pergunta-se: Se temos profissionais sendo formados todos os anos, como Engenheiros Agrônomos, Médicos Veterinários, Zootecnistas, Técnicos Agropecuários e tantos outros; conjugado com a falta de assistência técnica que a maioria dos agricultores tem, por que então não temos uma política capaz de mostrar como a assistência técnica poderia ajudar a viabilizar economicamente as propriedades e que os próprios agricultores passassem a remunerar estes serviços? Temos que romper o ciclo da pobreza onde os serviços públicos são oferecidos em teoria gratuitamente para todos, mas com uma qualidade questionável.

\section{Materiais e Métodos}

A metodologia constou de uma revisão bibliográfica sobre experiências desenvolvidas na área de ATER (Assistência Técnica e Extensão Rural) tanto por órgãos públicos como por instituições privadas e ONGs (Organizações Não Governamentais). Em relação ao Estado do Paraná foi analisado o documento denominado Identificação de Gargalos Tecnológicos da Agricultura Familiar: Subsídios e Diretrizes Para Uma Política Pública. Relatório 1 Levantamento das Demandas Tecnológicas e Sugestões de Diretrizes de Políticas Públicas; produzido pelo IPARDES (Instituto Paranaense de Desenvolvimento Econômico e Social) e pelo IAPAR (Instituto Agronômico do Paraná). Também foi realizada uma pequena pesquisa de campo apenas como sondagem, junto a agricultores associados ao Sindicato dos Trabalhadores Rurais de Piraí do Sul.

\section{Breve histórico da assistência técnica no Brasil}

Para entender melhor a assistência técnica rural é preciso fazer um pequeno histórico das organizações e suas formas de atuação. As organizações de ATER foram criadas nos anos 40 e 60 e posteriormente nos anos 70 enquadradas no sistema Embrater (Empresa Brasileira de ATER); possuíam estruturas hierarquirizadas do tipo militar, com objetivo de implantar a chamada revolução verde durante o também chamado período do Produtivismo Moder- 
nizador (Aumento de Produção com uso intensivo de insumos). Segundo Watts (1987) apud Caporal e Ramos (2006, p.17): "Quanto maior é o grau de funcionamento autocrático da administração central, tanto menos eficaz será a função educacional da extensão e tanto maior será sua utilização como veículo de política estatal".

As decisões sobre o que fazer, onde fazer, com quem fazer e como usar os recursos; devem caber mais a assistência técnica e aos agricultores, sendo acompanhados pelo Governo para que sigam os princípios e diretrizes da PNATER ${ }^{1}$. Concorda-se com Chambers apud Caporal e Ramos (2006) quando diz que os órgãos de pesquisa, extensão pública e principalmente as universidades e escolas técnicas devem ir com seus professores e alunos às comunidades, "principalmente quando solicitadas" (Observação e grifo nosso), para aprender, revisar currículos, reescrever livros, dar menos aulas e ajudar mais os outros a aprender. Isso igualmente serve para os políticos e as Ongs.

Hoje, é necessário trabalhar em parceria com a iniciativa privada; quer porque o Estado tem recursos limitados para investir e também porque temos todo ano profissionais de nível superior e médio sendo formados e procurando colocação no mercado de trabalho. O modelo de extensão rural pública que vigorou esgotou-se (ARAÚJO, 2004), não foi suficiente para evitar o empobrecimento da agricultura familiar; talvez até tenha contribuído para o êxodo rural e a diminuição do número de estabelecimentos existentes (SALES FILHO; SOUZA apud PARANÁ $^{2}, 2002$, p.1; ALVES, 1999, p.32 apud ALENTEJANO, 2000).

Pelos dados do IBGE 400 mil pequenos estabelecimentos agropecuários desapareceram nos dois primeiros anos do governo de Fernando H. Cardoso (FHC), assim como 1 milhão de empregos assalariados rurais (ALENTEJANO, 2000).

Alentejano (2000) critica o fato de que o Programa Nacional de Fortalecimento da Agricultura Familiar (PRONAF) excluir os agricultores que obtinham mais de $20 \%$ de sua renda familiar de

\footnotetext{
Política Nacional de Assistência Técnica e Extensão Rural. Para conhecê-la ver SILVA (2004). In. MOURA; FERRÃO NETTO, 2004, p.29.

2 GOVERNO DO ESTADO DO PARANÁ-SECRETARIA DE ESTADO DO PLANEJAMENTO E COORDENAÇÃO GERAL, Instituto Paranaense de Desenvolvimento Econômico e social, Instituto Agronômico do Paraná.
}

atividades não agrícolas, o que excluía a maior parte dos pluriativos ${ }^{3}$.

Importante também citar que Alves et al. apud Alentejano (2000) constatam que a baixa remuneração da agricultura, combinada com a atração das cidades está levando a um esvaziamento do campo e que prevalecendo está situação restarão apenas 600 mil estabelecimentos dos 4,9 milhões que existiam.

Caporal e Costabeber (1994) apud Caporal e Costabeber (2000, p. 02) já afirmavam o seguinte: "Não podemos nos deixar levar pelo imobilismo conservador que continua aprisionando as organizações públicas de extensão rural". Isto demonstra que a necessidade de mudanças na assistência técnica já vem fermentando a mais de dez anos. O tecnicismo calcado na otimização dos recursos/insumos como fertilizantes, sementes e agrotóxicos, seguiria sendo excludente sob o ponto de vista ambiental e não enfrentaria as questões chaves da sustentabilidade, na medida em que nela não há espaço para pensar-se a preservação da biodiversidade e nem mesmo respeitar a diversidade cultural. Não haveria preocupação com as externalidades ${ }^{4}$ (CAPORAL; COSTABEBER, 2000, p.05). Hoje esta visão reflete-se nas políticas do Ministério do Desenvolvimento Agrário / Secretaria de Agricultura Familiar/ Departamento de Assistência Técnica (MDA/SAF/DATER) onde Caporal exerce a função de Coordenador Geral de Assistência Técnica e Extensão Rural (ATER) e procura combater os desvios apontados em suas análises.

Os serviços de ATER devem propor um planejamento integrado das propriedades, mediante um uso equilibrado dos recursos naturais que possuem, selecionar as tecnologias mais adaptadas, priorizar o gerenciamento e a inclusão em mercados diferenciados. Se o atravessador leva a maior parte do lucro os agricultores devem organizar-se e exercerem essa função onde for possível. Quanto ao progresso técnico o próprio Costabeber apud Caporal e Costabeber (2000) reconhece que o processo de transição agroecológica não dispensa o progresso técnico e o avanço

\footnotetext{
Agricultores que exercem outras atividades que complementam sua renda, inclusive urbanas. Ex: Guias turísticos, pequenos comércios, empregados em fábricas e agroindústria e outras.

4 Efeitos externos ao mercado, geralmente efeitos ambientais negativos da agricultura moderna como alimentos contaminados, água contaminada, perda de recursos genéticos e uso de energias esgotáveis dos combustíveis fósseis.
} 
do conhecimento científico. Os autores afirmam ainda que a missão de qualquer estilo de extensão rural que se pretenda novo está destinada a ajudar no direcionamento de ações e atividades que promovam novos estilos de desenvolvimento e de agricultura que respeitem não só as condições específicas de cada agroecossistemas, mas também a preservação da biodiversidade e diversidade cultural.

Segundo os autores existem alguns princípios que devem nortear as ações de ATER, quais sejam:

- Buscar um crescente apoio à conservação e manejo de agroecossistemas sustentáveis.

- Apoiar os agricultores familiares na seleção de tecnologias capazes de reduzir riscos e otimizar o uso de recursos internos.

- Apoiar a consolidação de uma rede de parcerias envolvendo organizações públicas e privadas comprometidas com agricultura familiar.

$\mathrm{O}$ agricultor, especialmente o pequeno agricultor familiar sempre esteve no foco das políticas de assistência técnica, porém vivia e vive um dilema. Quando a assistência é de qualidade não atinge todos que precisam e quando se massifica perde a qualidade.

As características que definem a agricultura familiar são basicamente três:

1) As atividades de gestão e investimento são realizadas por indivíduos parentes ou ligados pelo matrimonio;

2) O trabalho é basicamente familiar;

3) A propriedade dos meios de produção pertence à família e é no seu interior que se dá a transmissão de propriedade.

Apesar disso existe uma enorme heterogeneidade, sendo reconhecidas também três grandes categorias conforme segue: (MAA ${ }^{5}, 1996$ apud CAPORAL; COSTABEBER, 2000).

1) Agricultores integrados ao mercado com acesso as inovações tecnológicas e políticas públicas;

2) Em transição; apesar de não possuírem acesso a maioria das políticas públicas e progra-

Ministério da Agricultura e Abastecimento. mas governamentais possuem amplo potencial para a sua viabilização econômica;

3) Periféricos; Estabelecimentos com precariedade de infra-estrutura, cuja integração a economia nacional depende de fortes e bem estruturados programas de reforma agrária, crédito, pesquisa ATER, agro industrialização, comercialização entre outros.

A ATER pública em que pesem seus defeitos é a maior rede técnica de apoio ao desenvolvimento de programas rurais, federais, estaduais ou municipais. As crises se intensificaram a partir de 1990 e agravaram-se com a extinção da EMBRATER ${ }^{6}$ em 1991. As medidas levaram a uma súbita e dramática retração do apoio técnico, administrativo, financeiro e político da esfera federal à extensão rural. Resultado disto foi que os estados reformaram as instituições com o propósito de reduzir dispêndios públicos e não para aumentar a qualidade dos serviços ou a efetividade em termos de custos ${ }^{7}$. Os resultados de forma geral foram a redução da capacidade de atendimento, prejudicando a assistência direta aos produtores e comunidades rurais e também os acessos a outros projetos governamentais.

Segundo o grupo de trabalho formado por Almeida et al. (N.D) que discutiu os papéis a serem desempenhados pelos sistemas de ATER no Plano de Desenvolvimento Regional da Amazônia as principais deficiências são: Insuficiência de pessoal, escassez de recursos financeiros, matriz institucional defasada, insuficiência de referências básicas sobre o modelo de desenvolvimento, desarticulação operacional entre instituições parceiras, desarticulação entre os modelos de desenvolvimento rural atuais e o modelo operacional da extensão rural, desconhecimento por parte de autoridades públicas da importância do papel e das potencialidades dos serviços na promoção do desenvolvimento, pouco controle da sociedade local. Guardadas as devidas diferenças regionais, mas considerando que os diferentes tipos de agricultores familiares ocorrem em todo o país,

\footnotetext{
6 Empresa Brasileira de Assistência Técnica e Extensão Rural.

7 Até hoje as reformulações estão acontecendo, foi o que aconteceu recentemente com a transformação da EMATER-PR que passou de empresa de administração indireta / vinculada a SEAB para Instituto ligado a administração direta.
} 
apenas com freqüências diferentes poderíamos dizer que as mesmas deficiências também ocorrem aqui no Estado.

\section{Aspectos gerais da assistência técnica rural}

Lacki $^{8}$ (2006) possui uma visão muito clara dos problemas enfrentados pelos agricultores familiares. Suas propostas e críticas se referem à falta de conhecimento das famílias rurais, aos métodos inadequados dos serviços de ATER e ao baixo nível educacional dos agricultores. Suas propostas são voltadas principalmente para as correções internas que os agricultores devem primeiramente fazer para depois criticarem o mercado, as políticas públicas, os políticos e organismos internacionais. Não adianta fazerem-se diagnósticos e apontar aquilo que está fora do alcance dos agricultores como causas de suas mazelas; isto servirá para deixá-los paralisados. Vejamos o que Lacki (2006, p.1-2) diz:

[...] os países ricos, gostemos ou não gostemos, estejamos ou não de acordo com suas políticas, continuarão, até onde lhes seja possível, subsidiando e protegendo os seus agricultores; e os paises pobres continuarão sem força política para impedir que os países ricos continuem fazendo-o.

Na seqüência conclui que:

[...] nossas tecnologias que já estão disponíveis, porém ociosas / subutilizadas devido as inaceitáveis debilidades dos nossos serviços de extensão rural. E tudo isso depende especialmente dos próprios agricultores, com a única condição que os governos lhes proporcionem nada mais que os conhecimentos necessários para que eles saibam corrigir as deficiências tecnológicas, gerenciais e organizacionais que ainda caracterizam a maioria dos produtores rurais.

Segundo Grzybowski (1991) as crises financeiras dos Estados os impedem de ampliar os serviços oficiais de ATER, porém é imprescindível que as inovações cheguem efetivamente a maioria dos agricultores e que eles sejam capacitados para adotá-las integral e corretamente. Em vista disto é

\footnotetext{
8 Polan Lacki, Engenheiro Agrônomo, natural de Foz do Iguaçu, filho de Agrônomo e agricultor, ex extensionista rural do Paraná e Piauí e ex-consultor da FAO-ONU (Nações Unidas) por 23 anos para América Latina
}

preciso buscar alternativas que permitam ampliar o número de famílias atendidas utilizando, de forma mais racional os recursos existentes.

Brose (2000, p.55) cita que o Departamento Norte Americano de Agricultura (USDA) e o Serviço de Extensão Rural Norte Americano (CSREES) criaram um programa emergencial de apoio a pequenos produtores com oito objetivos estratégicos (USDA, 1999), a saber:

1- Fomentar os potenciais da pequena propriedade,

2- Criar uma rede de apoio,

3- Promover, desenvolver e reforçar mercados justos, competitivos e abertos,

4- Descentralizar e integrar os serviços de extensão rural,

5- Garantir a formação de novas gerações de produtores,

6- Enfatizar a agricultura sustentável como uma estratégia rentável, ecológica e socialmente adaptada para a pequena propriedade,

7- Alocar recursos orçamentários para fortalecer a competitividade da pequena propriedade na agricultura americana.

Conforme consta em BRASIL apud Caporal e Ramos (2006, p.06) cabe a extensão rural dentro da nova política de ATER,

estimular, animar e apoiar iniciativas de desenvolvimento rural sustentável, que envolvam atividades agrícolas e não agrícolas, pesqueiras, de extrativismo e outras, tendo como centro o fortalecimento da agricultura familiar, visando a melhoria de qualidade de vida e adotando os princípios da agroecologia como eixo orientador das ações.

O fato significativo é fazer com que os agricultores que queiram, possam ter acesso a uma orientação técnica. Sem haver contato entre o técnico e o agricultor nenhuma terá sucesso. De acordo com Caporal e Ramos (2006) não existe ainda uma relação estabelecida entre as famílias que um técnico pode atender concretamente. Algumas experiências sugerem 100 famílias por técnico. Considera-se esse número exagerado, mesmo em condições ideais de 
proximidade. É necessário estabelecer projetos piloto onde o responsável técnico fará seu plano de atividades junto aos agricultores.

\section{Assistência técnica pública e privada}

O início significativo do assessoramento técnico aos agricultores deu-se por meio de iniciativas públicas, principalmente aos agricultores de menor porte, entretanto hoje a iniciativa privada também atua neste meio com sucesso, e isto é um desafio permanente para os profissionais. Se os conhecimentos forem suficientes para melhorar as chances de sucesso econômico das propriedades rurais deverão ser procurados pelos agricultores.

\section{Aspectos da Assistência Técnica Pública}

A EMATER-PR ${ }^{9}$ possui uma grande estrutura, estando presente em 393 municípios e 14 unidades distritais. Possui 1412 funcionários, sendo 222 cedidos por prefeituras e outras instituições. Possui 365 Engenheiros Agrônomos, 344 técnicos agrícolas, 46 médicos Veterinários, 33 Zootecnistas e 234 auxiliares. Os demais são outros profissionais de nível médio e superior.

O público atendido é formado por agricultores familiares em sua grande maioria, sendo que foram assistidas 144.000 famílias em 2005 e mais 25.000 famílias de trabalhadores rurais, pescadores artesanais, jovens rurais, mulheres rurais, empresários rurais (2.872) e outros. O planejamento das ações em 2006 buscou captar as expectativas dos parceiros em relação ao trabalho a ser desenvolvido e discutir possibilidades de ampliação ou redirecionamento das ações já desenvolvidas. Há uma forte parceria com os municípios, o que por um lado é favorável por ter o apoio local, mas por outro se verifica uma forte conotação política, muitas vezes com interferências na atuação técnica com prejuízos evidentes aos agricultores. Somente um controle social é que evitará disputas políticas nesse sentido.

Analisando agora algumas ações da EMATER-PR podem-se destacar duas ações que em nosso entender mostram bem que se houver melhoria na ATER; a resposta em produtividade é palpável. Segundo o relatório de atividades de 2005 o Programa

\footnotetext{
Instituto Paranaense de Assistência Técnica e Extensão Rural.
}

de geração e Ocupação de Renda denominada Orientação Diferenciada na Produção de Grãos foi positivo nesse sentido. É feito um acordo de metas para 5 anos entre o produtor e os técnicos e assim persegue-se o aumento de produtividade e o que é mais importante, de rentabilidade. O programa conseguiu que as lavouras de milho tivessem produtividades $14,6 \%$ maiores que a média do estado e rentabilidade $25,3 \%$ superior à média estadual. A soja produziu $9,1 \%$ a mais que a média estadual e a rentabilidade ficou $18,4 \%$ acima da média. $\mathrm{O}$ uso de agrotóxicos reduziu-se em 11,8\%. Para assegurar estes resultados em 329 unidades produtivas os 37 profissionais vivem um processo de capacitação contínua e os produtores recebem assistência técnica sistemática em suas propriedades.

Outro projeto interessante da EMATER-PR é o projeto Grãos-Centro Sul de Feijão e Milho; que trata da profissionalização de agricultores nas lavouras tradicionais de feijão e milho numa visão de desenvolvimento, na qual, por meio do aumento da produtividade, da produção e da renda seja possível gerar poupança para a introdução de outras atividades. Este projeto envolve 39 técnicos mais um grupo base de 11 pessoas que difundem os conhecimentos a um total de 1220 produtores de feijão e 980 de milho. Este projeto é uma parceria entre o Governo do Paraná, Embrapa, Fundação Terra e a empresa multinacional de agrotóxicos Syngenta.

Analisando o trabalho denominado A Disponibilidade de Assistência Técnica nos Projetos de Assentamento do INCRA, Sparovek et al. (2004) ${ }^{10}$, constata-se que apenas 14\% das famílias em média, no Brasil, possuem assistência; no Paraná, esse número sobe um pouco para $21 \%$. Sparovek, Maule e Cooper concluem que há pouca oferta de assistência técnica e que o Estado é o principal agente.

Várias entidades já estão cadastradas para atuar em serviços de ATER de acordo com a nova política nacional de ATER. São Paulo, por exemplo, possuem um cadastro com o nome da instituição, e-mail e o nome do responsável, facilitando o acesso dos interessados. Ex: Associações de produtores, cooperativas, unidades da CATI (Coordenadoria de Assistência Técnica Integral), sindicatos rurais, prefeituras municipais/secretarias municipais, escolas,

${ }_{10}$ In MOURA e FERRÃO NETTO, 2004, p.166. 
firmas de planejamento e inclusive uma cooperativa de assistência técnica e extensão rural. As ações do MDA em ATER existem e estão divulgadas. São baseadas na Constituição Federal de 1988 e na Lei Agrícola de 1991 e mais recentemente na Lei da Agricultura Familiar n ${ }^{\circ}$ 11.326/06 que atribuem especialmente à União à responsabilidade de prover os agricultores familiares com serviços de ater gratuitos. Maiores informações podem ser obtidas nos sites $<$ www.mda.gov.br/saf $>$ e $<$ www.pronaf.gov.br $>$.

\section{Aspectos da Assistência Técnica Privada.}

Os agricultores em geral e não apenas os agricultores familiares precisam dar mais valor aos profissionais que trabalham na área rural. Conforme Graziano (2006) $)^{11}$ o mercado seletivo e rigoroso massacra o agricultor, mesmo com tanta tecnologia está difícil pagar os custos de produção. Mais que saber plantar, os agricultores devem gerenciar seus negócios de forma empreendedora, competitiva, aplicar e conhecer as boas práticas e fazer agricultura sustentável.

Um programa divulgado no Congresso de Assistência Técnica à Agricultura despertou a atenção pela similaridade com a proposta contida neste trabalho. É o PAF - Programa Agrônomo da Família, onde uma equipe multidisciplinar trabalharia na sua estruturação, podendo ser composta ainda por lideranças de comunidades e técnicos agrícolas. $\mathrm{O}$ Engenheiro Agrônomo atenderia a certo número de agricultores e se inter-relacionaria com a equipe multidisciplinar, com os órgãos de pesquisa, ensino e extensão; visando remover os problemas que irão surgindo com o decorrer do tempo. Seria avaliado por um conselho com a participação dos agricultores. O financiamento deveria ser dividido pelo poder público nas três esferas; Municipal, Estadual e Federal; a contratação das equipes poderia ser feita pelo poder público ou por organizações terceirizadas como ONGs e Organizações da Sociedade Civil e que tenham o controle dos agricultores, técnicos e do poder público (ALVES SOBRINHO, 2004) ${ }^{12}$.

Exemplos bem sucedidos de assistência técnica são as experiências da COPLACANA (Cooperativa

11 Eng $^{\circ}$ Agrônomo, Foi presidente do INCRA (1995) e Secretario de Agricultura de São Paulo (1996-1998). Artigo publicado no jornal O Estado de São Paulo, p.A2 - 10.10.2006.

12 In MOURA e FERRÃO NETTO, 2004, p.156. dos Plantadores de Cana) e da AFOCAPI (Associação dos Fornecedores de Cana) de Piracicaba-SP, que possuem um Departamento Agronômico (DTA) que desempenha importante trabalho de assistência técnica qualificada e diária aos seus associados.

\begin{abstract}
A assistência técnica é intensiva, direta, diária e personalizada, refletindo positivamente na produção de qualidade. Atestam a viabilidade do cooperativismo e do associativismo e que a assistência técnica ao homem do campo e ao sistema produtivo é uma forma de conduzir corretamente a produção, promover economia, diminuir custos, economizar energia, diminuir gastos de verbas públicas com melhor utilização de recursos. Resta ao Estado fortalecer seu sistema de ATER, importante para o melhor aproveitamento das áreas agricultáveis e para a verticalização da produção. (FARHAT, 2004) $)^{13}$.
\end{abstract}

Merece destaque o fato de que $72 \%$ dos associados da COPLACANA são mini e pequenos produtores, totalizando 4.344 produtores.

\section{Necessidade de Assistência Técnica no Paraná}

A importância da assistência técnica está bem demonstrada no trabalho desenvolvido pelo IPARDES (Instituto Paranaense de Desenvolvimento Econômico e Social) e pelo IAPAR (Instituto Agronômico do Paraná) no ano de 2004. O trabalho chama-se: Identificação de Gargalos Tecnológicos da Agricultura Familiar: Subsídios e Diretrizes Para Uma Política Pública. Relatório 1 - Levantamento das Demandas Tecnológicas e Sugestões de Diretrizes de Políticas Públicas. O estudo faz uma ampla tabulação dos problemas, causas e soluções propostas. Segundo PARANÁ $\left(2005\right.$, p.51) ${ }^{14}$, analisando os dados do Censo de 1995 do IBGE constata-se que apenas $33,3 \%$ dos estabelecimentos classificados como familiares puros fazem uso da assistência técnica, dos familiares empregadores $50,1 \%$ e dos classificados como empresariais $60,8 \%$. Veja Tabela 1 , à seguir transcrita:

\footnotetext{
3 In MOURA e FERRÃO NETTO, 2004, p.196.

14 GOVERNO DO ESTADO DO PARANÁ-SECRETARIA DE ESTADO DO PLANEJAMENTO E COORDENAÇÃO GERAL, Instituto Paranaense de Desenvolvimento Econômico e social (IPARDES), Instituto Agronômico do Paraná (IAPAR)
} 
Tabela 1 - Proporção de estabelecimentos com presença do indicador tecnológico segundo o tipo de estabelecimento 1995

\begin{tabular}{c|c|c|c|c|c}
\hline \multirow{2}{*}{$\begin{array}{c}\text { TIPO DE } \\
\text { ESTABELECIMENTO }\end{array}$} & \multicolumn{4}{|c}{ PROPORÇÃO DE ESTABELECIMENTO COM PRESENÇA DO INDICADOR } \\
\cline { 2 - 5 } & $\begin{array}{c}\text { Uso de } \\
\text { Técnictência (\%) }\end{array}$ & $\begin{array}{c}\text { Uso de Adubos e } \\
\text { Corretivos (\%) }\end{array}$ & $\begin{array}{c}\text { Práticas de } \\
\text { Conservação } \\
\text { de solo (\%) }\end{array}$ & $\begin{array}{c}\text { Associado à } \\
\text { Cooperativa (\%) }\end{array}$ & $\begin{array}{c}\text { Total de } \\
\text { Estabelecimentos (Abs.) }\end{array}$ \\
\hline Familiar Puro & 33,3 & 61,5 & 42,3 & 22,1 & 216.069 \\
\hline Familiar empregador & 50,1 & 76,2 & 60,4 & 35,4 & 78.696 \\
\hline Empresarial & 60,8 & 70,1 & 60,1 & 39,0 & 32.846 \\
\hline Total & 40,1 & 67,3 & 48,4 & 27,0 & 327.611 \\
\hline
\end{tabular}

Fontes: IBGE - Censo Agropecuário (microdados); Ipardes, Iapar - Tabulações especiais; PARANÁ (2005.p. 51).

O desafio aos extensionistas é a diversidade de sistemas produtivos que exige uma visão integrada.

Outro aspecto percebido é de que a assistência técnica, quase sempre atuando em várias frentes relacionadas aos diversos programas de governo, envolvendo muitas áreas de trabalho - é deficiente em oferecer aos seus técnicos a capacitação e atualização necessária para o adequado desempenho desses agentes em respostas as demandas dos agricultores. (PARANÁ, 2005, p.79).

\section{Proposta}

\section{Justificativa}

Em qualquer região a difusão de tecnologia, pública ou privada é o elo entre a pesquisa e a produção. Nas regiões de concentração dos públicos prioritários da extensão oficial há uma predominância de uma população de baixo nível de conhecimento e com dificuldades de acesso a novas tecnologias. Os modelos de municipalização parecem ser o caminho natural da ATER, porém os gestores municipais demonstram em sua maioria que não estão maduros suficientemente para entender o potencial transformador que a ATER possui; pois a utilizam com objetivos políticos muitas vezes, deixando os profissionais inseguros para realizarem seu trabalho e conseqüentemente não se comprometendo com os resultados.

\section{Objetivos da proposta}

1- Propiciar ATER (Assistência Técnica e Extensão Rural), a agricultores familiares, principalmente, mas não exclusivamente, durante o primeiro ano de forma gratuita;

2- Criar uma rede de ATER participativa;

3- Planejar integralmente a propriedade junto com o agricultor;

4- Aumentar a renda agrícola do agricultor;

5- Despertar o agricultor para o valor do assessoramento técnico, de forma que ele continue com a assistência técnica após um ano;

6- Facilitar o acesso a todos os programas governamentais por meio da rede de ATER montada;

7- Gerar empregos para profissionais que atuam no meio rural, como Eng ${ }^{\circ}$ Agrônomos, técnicos agropecuários e outros profissionais.

\section{Funcionamento da proposta}

A proposta prevê que o governo estadual banque no primeiro ano do programa a assistência técnica para os agricultores que assim desejassem aderir voluntariamente ao programa, com o único compromisso de planejarem sua propriedade em conjunto com os técnicos, executando as tarefas conforme o combinado; por isso a importância da adesão voluntária. Após este período de contato e trabalho com a assistência técnica o agricultor e o grupo que lhe presta assistência vão negociar a continuidade dos serviços baseados nos aumentos de renda que a propriedade obteve ou foi capaz de gerar. As políticas 
de Governo e de Estado para o meio rural, como financiamentos, custeios, investimentos, defesa sanitária animal e vegetal, agroindústrias seriam realizadas através deste canal, priorizando os agricultores inseridos neste programa.

O programa seria desenvolvido com um Engenheiro Agrônomo (ou outro profissional de nível superior) coordenando uma equipe de 10 técnicos agrícolas que por sua vez atenderiam 100 propriedades rurais em cada município. O ideal seriam 10 produtores por técnico agrícola, de modo que cada agricultor destinasse aproximadamente 150 sacos de milho anuais (15 sacos/mês) ou 15 litros de leite/ dia para futuro pagamento no ano seguinte do Eng ${ }^{\circ}$ Agrônomo que ganharia $\mathrm{R} \$ 2500,00$ reais e do Técnico Agrícola que ganharia R\$ 1500, 00 reais/mês. As lavouras de feijão, criação de gado leiteiro e de corte, batata, fruticultura, criação de peixes, hortaliças e demais atividades da propriedade que proporcionassem mais renda seriam do agricultor. Talvez nem fosse necessário aumentar a produção, mas apenas reduzir custos desnecessários para aumentar a renda. O projeto levaria conhecimento técnico, gerencial, organizacional, de mercado e outros. É uma aposta no insumo pessoa, recurso humano, onde os técnicos procurarão com os recursos disponíveis, principalmente dentro das propriedades, melhorarem o rendimento das atividades, comercialização dos produtos e a renda, mostrando aos agricultores que é vantajoso investir na assistência técnica. É um desafio para os técnicos e para os agricultores com um subsídio do governo no primeiro ano. É necessário que os técnicos possuam condições próprias de se deslocar até as propriedades sempre que for necessário. A proposta estima um custo anual por família de $\mathrm{R} \$ 2.275,00$ reais por ano ou o equivalente a 146,77 sacos de milho / ano (12,2 sacos / mês) ao preço de $\mathrm{R} \$ 15,50$ reais o saco de milho $(60 \mathrm{~kg})$. Se a referência fosse litros de leite, seriam destinados aproximadamente 15 litros de leite ao dia para pagar a assistência técnica ( $\mathrm{R} \$ 189,00$ reais divididos por $\mathrm{R} \$ 0,45=420,22$ divididos por 30 dias $=14$ litros); estes, perfeitamente possíveis de se obter com apenas uma vaca leiteira em um hectare ou menos, com alimentação apenas em pastagens. Será que este custo é alto para o agricultor ter assistência técnica integral em toda sua propriedade rural? Há que se por a prova e enfrentar o desafio.

\section{Aspectos positivos}

O governo não necessitará novamente dispender recursos, podendo implantar o programa em uma nova região ou se dedicar a investir na infraestrutura local obtendo mais chances de sucesso em fixar a população no interior e fazer chegar os programas governamentais até eles. Poderá gerar muitos empregos. Para os agricultores a assistência estará mais presente, atuando efetivamente para evitar que os problemas aconteçam e quando acontecerem ajudar efetivamente a solucioná-los ou buscar a solução junto com os agricultores. Os agricultores não perderão nada com a proposta, apenas terão um ano para conviver com a assistência técnica e depois decidir se valerá a pena continuar. Para os profissionais será um grande desafio, pois poderão exercer suas profissões com toda criatividade e liberdade, em busca de soluções e terão que provar o seu valor. Já para a sociedade os benefícios poderão vir na redução das externalidades ambientais, como, reduções da erosão dos solos, poluição das águas, conservação das matas e nascentes, não contaminação de alimentos por agrotóxicos e fixação da população rural no campo com melhor qualidade de vida, diminuindo o êxodo para as periferias das cidades maiores.

\section{Avaliação da proposta}

O programa será permanentemente avaliado por uma coordenação da SEAB, junto com o Eng ${ }^{\circ}$ $\mathrm{Agr}^{\circ}$, os técnicos e os agricultores principalmente. Se houver incapacidade técnica ou incompatibilidade com o programa os integrantes poderão ser substituídos a qualquer momento pela coordenação, após considerar a opinião de todos os participantes. É importante que o programa seja o menos burocrático possível dando liberdade a imaginação e criatividade dos técnicos. Isso não quer dizer que não vá possuir controles, acompanhamento e avaliações constantes.

Dentro desta proposta podemos utilizar os indicadores de impactos e de processos na sua avaliação, que foram sugeridos por Caporal e Ramos (2006, P.13), os quais são:

1- Indicadores do Processo de Transição Agro ecológica: Redução do uso de insumos 
químicos como os agrotóxicos, melhorias do solo, uso de tecnologias de base ecológica como inseticidas biológicos, adubos orgânicos, redução de impactos ambientais (erosão do solo, redução queimadas, proteção de nascentes).

2- Indicadores Sociais: Melhorias na alimentação das famílias, participação de jovens e mulheres, acesso à saúde e previdência, melhorias na habitação, disponibilidade de água, energia e educação.

3- Indicadores Econômicos: Melhoria na renda, acesso aos mercados, ocupação de mão de obra, adimplência ou inadimplência creditícia, dependência de insumos externos, diversidade e estabilidade da produção;

4- Indicadores Relacionados à Cultura Local: Práticas e tecnologias adaptadas, produção de subsistência compatível com os hábitos alimentares, ação extensionista compatível com os valores e modos de vida da comunidade;

5- Indicadores de Gestão Institucional: Democratização e integração intra e interinstitucional na gestão e na execução das ações.

Trabalhando-se estes indicadores constantemente, pode-se monitorara os processos em andamento, avaliar a eficiência das práticas propostas, fazer um processo de retro alimentação e redirecionamento das ações quando necessário.

\section{Conclusões}

Verificou-se e confirmou-se que a assistência técnica e extensão rural foram e ainda são importantes para ampla maioria dos agricultores, especificamente os agricultores familiares. Sua forma de atuação vem sendo questionada e desafiada a ser mais participativa e incluir os agricultores cada vez mais nos processos de decisão.

Existem ainda muitas deficiências nos processos como malversação no uso de recursos e metodologias não tão adequadas; as organizações estão se reestruturando e abrindo espaços para novas organizações, instituições, associações ONGs e empresas para atuarem com agricultura familiar, buscando com isso atingir cada vez mais agricultores e prestar-lhes um serviço adequado.

No Estado do Paraná ficou bem claro no estudo feito pelo IPARDES e IAPAR que a maioria dos problemas tecnológicos que ocorrem na agricultura familiar são até certo ponto fáceis de resolver. São questões técnicas, na maioria de solução conhecida, porém que não chegam ao conhecimento ou ao alcance dos agricultores.

Sugere-se a implantação de um projeto piloto com os agricultores associados ao sindicato dos Trabalhadores Rurais de Piraí do Sul. Sugere-se também a formação de um grupo estratégico de apoio formado pela UEPG, Embrapa, IAPAR, IPARDES, FETAEP, SEAB, EMATER, Empresas Interessadas, ONGs ou Profissionais que queiram colaborar.

\section{Agradecimentos}

Ao Professor Orientador Luis Antonio Brandalise do departamento de Economia - UEPG pelas orientações e estímulo. A Professora Cleise Hilgemberg, coordenadora do Curso de Especialização em Formulação e Gestão de Políticas Públicas e por extensão a todos os demais professores que contribuíram com suas experiências, ao Governo do Estado e a Secretaria de Estado da Agricultura por terem disponibilizado esta oportunidade por meio do Programa Escola de Governo, ao colega de trabalho Médico Veterinário Olavo Costa Filho, ao Sr. José Roberto Ferreira, Presidente do Sindicato dos Trabalhadores Rurais de Piraí do Sul e finalmente a minha esposa e companheira Líliam D. da Silva Sassi pelo apoio constante na realização deste trabalho.

\section{Referências}

ALENTEJANO, P. R. R. O que há de novo no rural brasileiro? Terra Livre, São Paulo, n.15, p.87-112, 2000.

ALMEIDA et al. Subsídios para a reformulação da extensão rural no contexto do plano de desenvolvimento regional da Amazônia: síntese das conclusões dos grupos de trabalho. Disponível em: <http://www.suframa.gov.br/ download/publicacoes/extruturavfinal.pdf $>$. Acesso em 13 novembro 2006.

ALVES SOBRINHO, F. F. Programa Agrônomo da Família - PAF: uma proposta de extensão rural para a agricultura familiar. In: MOURA; FERRÃO NETTO. (Ed.). CONGRESSO BRASILEIRO DE ASSISTÊNCIA 
TÉCNICA À AGRICULTURA. OS CAMINHOS DA ASSISTÊNCIA TÉCNICA À AGRICULTURA. Anais... Piracicaba: FEALQ: AGROESP, 2004. 572 p. il.

ARAÚJO, R, T de. A Práxis da Educação Ambiental: O Próximo Desafio da Extensão Rural Paulista. In: CONGRESSO BRASILEIRO DE ASSISTÊNCIA TÉCNICA À AGRICULTURA. OS CAMINHOS DA ASSISTÊNCIA TÉCNICA À AGRICULTURA, 2004, Piracicaba. Anais... Piracicaba: FEALQ: AGROESP, 2004. p.234-239.

BROSE, M. Fortalecendo a democracia e o desenvolvimento local: 103 experiências inovadoras no meio rural gaúcho. Santa Cruz do Sul: EDUNISC, 2000. $451 \mathrm{p}$.

CAPORAL, F. R.; COSTABEBER, J. A. Agroecologia e desenvolvimento rural sustentável: Perspectivas para uma nova extensão rural. Agroecologia e Desenvolvimento Rural Sustentável. Porto Alegre, v.1, n.1, jan./mar.2000. Disponível em: <http://www.agroecologia.uema.br/ publicacoes/CaporaleCostabeberUm.pdf $>$. Acesso em: 20 outubro 2006.

CATI. Sistema para cadastramento das organizações de ATER. Disponível em: <http://www.cati.sp.gov.br/ novacati/ater/index.htm>. Acesso em 01/11/2006.

CAPORAL, F. R.; RAMOS, L. F. Da Extensão rural convencional à extensão rural para o desenvolvimento sustentável: enfrentar desafios para romper a inércia. Brasília, Set/2006. Texto em Fase de Publicação. Disponível em: $<$ http://www.pronaf.gov.br/dater/arquivos/0730612230. pdf $>$. Acesso em: 01 novembro 2006.

EMATER-PR. Instituto paranaense de assistência técnica e extensão rural: relatório de atividades 2005. Curitiba, 2005. $65 \mathrm{p}$.

FARHAT, M. Assistência técnica: uma atribuição das entidades associativas e cooperativas de produtores rurais no agronegócio - experiência da COPLACANA e AFOCAPI. In: CONGRESSO BRASILEIRO DE ASSISTÊNCIA TÉCNICA À AGRICULTURA. Os Caminhos da Assistência Técnica À Agricultura, 2004, Piracicaba. Anais... Piracicaba: FEALQ: AGROESP, 2004. p.190-197.

GRAZIANO, Xico. Agronomia do futuro. Estado de São Paulo, São Paulo, p.A2, 10/10/2006.

GRZYBOWSKI, L. M. Desenvolvimento rural: soluções simples para problemas complexos. Rio de Janeiro: AS-PTA, 1991, p.14. Traduzido de: Desarrolo Rural: soluciones simples para problemas complejos, Santiago, Oficina Regional de la FAO para América Latina y el Caribe, 1988, 39p.

LACKI, Polan. Estamos "paralisando" os agricultores com diagnósticos equivocados e com soluções demagógicas. Disponível em: <http://.polanlacki.com.br/ artigosbr/paralisisbra.rtf>. Acesso em: 24 de outubro 2006.
PARANÁ. Identificação de gargalos tecnológicos da agricultura familiar. Subsídios e diretrizes para uma política pública: relatório 1: levantamento das demandas tecnológicas e sugestões de diretrizes de políticas públicas /Instituto Paranaense de Desenvolvimento Econômico e Social, Instituto Agronômico do Paraná. Curitiba: IPARDES, 2005, 318p. Disponível em: <http://www. ipardes.gov.br/webisis.docs/seti_gargalos_agricultura familiar_relatorio_01_2005.pdf>. Acesso em: 20/10/2006.

SILVA, A. M. Política Nacional de Assistência Técnica e Extensão Rural. In: MOURA; FERRÃO NETTO. (Ed.). CONGRESSO BRASILEIRO DE ASSISTÊNCIA TÉCNICA À AGRICULTURA. OS CAMINHOS DA ASSISTÊNCIA TÉCNICA À AGRICULTURA. Anais.. Piracicaba: FEALQ: AGROESP, 2004. p.29.

SPAROVEK, G. et al. A disponibilidade de assistência técnica nos projetos de assentamento do INCRA. In: CONGRESSO BRASILEIRO DE ASSISTÊNCIA TÉCNICA À AGRICULTURA. OS CAMINHOS DA ASSISTÊNCIA TÉCNICA À AGRICULTURA, 2004, Piracicaba. Anais... Piracicaba: FEALQ: AGROESP, 2004. p.165-169. 